selbe $0,41 \%$. Unter Berücksichtigung dieses Gehaltes und bei Anwendung von Formel 13 wird:

$$
p_{c}^{\prime}=\frac{20,96.610,85+0,4.31,36}{31,36 \cdot 103,07} \cdot \frac{0,03012}{0,02449}=4,88 .
$$

Zwei Kohlenoxydbestimmungen, die Herr Dr, Ehrenberg mit mir. gleichzeitig für dasselbe Leuchtgas, aber nach Bunsen's Methode, ausführte, ergaben die Zahlen 4,82 und 5,01, also im Mittel 4,92 Procent.

Tübingen, im Juli 1884.

\title{
Ueber Isatin;
}

von

H. Kolbe.

\section{(Vorläufige Mittheilung.)}

Man kann mir, meine ich, keinen Vorwurf daraus machen, dass ich die seit Jahren im hohen Grade mich interessirenden chemischen Verbindungen jetzt auch zum Gegenstande einer Experimental-Untersuchung mache, welche seit länger als einem Jahrzehnt, so zu sagen, die Domäne von Adolf Baeyer gewesen sind: das Isatin und das Indigblau. Auch in der Chemie gilt das Recht der Verjährung.

Man wird es begreiflich finden, dass ich bei meiner Untersuchung die Chimären der Strukturchemie unberücksichtigt lasse, und den von Berzelius vorgezeichneten Weg gehe, welcher mich $40 \mathrm{~J}$ ahre lang immer gut geführt hat.

Gleich die ersten Versuche haben ein befriedigendes Resultat gebracht. Es galt, meine unlängst ausgesprochene Vermuthung '), das Isatin möge eine Verbindung von Formyl mit Stickstoffbenzoyl, demjenigen Derivat des Benzoyls sein, dessen Phenyl eins seiner fünf Wasserstoffatome durch ein Atom einwerthigen Stickstoffs ersetzt enthält, auf ihren

1) S. dies. Journ. [2] 27, 490 ff. 
Werth und ihre Haltbarkeit zu prüfen. - Ist diese Vorstellung richtig, so darf man hoffen, dass durch Oxydirung des Isatins aus dessen Formyl Carboxyl wird, und dass so aus Stickstoffbenzoyl-Formyl, Stickstoffbenzoyl-Carbonsäure hervorgeht.

Die gewöhnlichen Oxydationsmittel, welche die Mehrzahl der Aldehyde in die zugehörenden Säuren verwandeln, versagen bier den Dienst, so auch die Lösung von chromsaurem Kali in verdünnter Schwefelsäure; leicht aber bewirkt, wie ich gefunden habe, Chromsäure jene Oxydation, wenn man den Process in Eisessig (auch Essigsäure-Anhydrid) sich vollzieben lässt. Die Flüssigkeit füllt sich zuerst mit amorphen braunen Flocken, welche sich später in kleine Krystalle verwandeln, die, auf einem Saugfilter gesammelt und mit Wasser ausgewaschen, ein schweres, sandiges, gelbes Krystallpulver darstellen. - Man gewinnt davon gegen 80 Procent rom Gewicht des angewendeten Isatins.

Dieses Produkt enthält ein Atom Sauerstoff mehr, als das Isatin, nämlich $\mathrm{C}_{8} \mathrm{H}_{5} \mathrm{NO}_{3}=\mathrm{C}_{6}\left\{\begin{array}{l}\mathrm{H}_{4} \\ \mathrm{~N}\end{array}\right\} \mathrm{CO} . \mathrm{COOH}$, und kann als Stickstoffbenzoyl-Carbonsäure aufgefasst werden. Bis die Frage entschieden ist, ob dieselbe nicht ein doppelt so hohes Moleculargewicht hat, und ob sie eine ein- oder zweibasische Säure ist, will ich sie, um ihre Beziehung zum Isatin anzudeuten, "Isatosäure" nennen.

Diese Isatosäure ist in kaltem Wasser und Alkohol wenig löslich, leichter in den heissen Flüssigkeiten, krystallisirt aus heissem Wasser in langen Nadeln, aus siedendem Alkohol in gelben rhombischen Tafeln. Sie ist eine schwache Säure, verbindet sich mit Basen zu Salzen; sie erleidet mancherlei bemerkenswerthe Zersetzungen, welche geeignet scheinen, über ihre chemische Constitution und damit rückwärts über die des Isatins weiteren Aufschluss zu geben. Wo man dieselbe anfasst, erweist sie sich dem Beobachter durch Eröffnung von oft ganz unerwarteten Ausblicken dankbar.

Wenige Grade über ihren Schmelzpunkt erhitzt, erleidet sie Zersetzung in Kohlensäure und eine bis jetzt noch nicht 
weiter untersuchte Substanz. Auch durch längeres Kochen mit Wasser wird sie unter Ausgabe von Kohlensäure verändert. - Siedendes Barytwasser erzengt damit reichliche Mengen von kohlensaurem Baryt, und das lösliche Barytsalz einer in Wasser leicht löslichen, daraus in farblosen, langen Nadeln krystallisirenden Säure. Damit scheint diejenige Säure identisch zu sein, welche aus der Isatosäure durch Erhitzen mit mässig verdünnter Schwefelsäure (1 Thl. Schwefelsäurehydrat und $1 \mathrm{Thl}$. Wasser) im Kochsalzbade entsteht, unter gleichzeitiger Entwickelung reichlicher Mengen von Kohlensäure. Das Produkt gesteht beim Erkalten mit der überschüssigen Schwefelsäure zu einem Magma farbloser langer, dünner Blättchen.

Der Versuch, die Isatosäure in alkoholischer Lösung mit Salzsäure zu ätherificiren, hat ein unerwartetes Resultat gegeben. Durch Erhitzen des in der Kälte mit Salzsäuregas gesăttigten Alkohols geht die darin suspendirte Isatosäure in Lösung, und mit dem Salzsäuregas entweicht viel Kohlensäure. Die schliesslich klare Lösung setzt während des Erkaltens eine grosse Menge farbloser Krystalle ab, welche durch Absaugen auf einem Trichter mit Glaswolle von der sauren Mutterlauge getrennt, und im Exsiccator iiber Aetzkalk getrocknet, in trockner Luft sich unverändert halten. Diese Krystalle enthalten Salzsäure in chemischer Verbindung mit einem flüssigen Aether (wie es scheint, dem Aethyläther der Stickstoffphenyl-Carbonsäure:

$$
\left.\mathrm{C}_{6}\left\{\begin{array}{c}
\mathrm{H}_{4} \\
\mathrm{~N}
\end{array}\right\} \mathrm{COOC}_{2} \mathrm{H}_{5}\right)
$$

und einer festen sublimirbaren Säure. Dieselben zerfallen in Berührung mit Wasser in Salzsäure, jenen Aether, der sich als $\mathrm{Oel}$ von sehr angenehmem Geruch abscheidet und die mit der Salzsäure in Lösung bleibende Säure (vermuthlich von der Zusammensetzung: $\left.\mathrm{C}_{6}\left\{\begin{array}{c}\mathrm{H}_{4} \\ \mathrm{~N}\end{array}\right\} \mathrm{C}\left\{\begin{array}{c}\mathrm{H} \\ \mathrm{OH}\end{array}\right\} \mathrm{COOH}\right)$. Das flüchtige Oel lässt sich mit Wasserdampf abdestilliren und aus dem milchigen Destillat mit Aether ausziehen. Die in der Retorte zurückbleibende saure Flüssigkeit, durch $\mathrm{Ab}$ dampfen auf dem Wasserbade von Salzsäure befreit, hinter- 
Gumpert: Ueb. d. Zersetzung des Benzonitrils etc. 87

lässt eine krystallinische Säure, welche bei $100^{\circ}$ langsam in wolligen lockeren Flocken sublimirt.

Die Isatosäure lässt sich direct auch aus reinem Indigblau durch Oxydiren mit Chromsäure unter Eisessig darstellen.

Ueber obige Zersetzungsprodukte der Isatosäure, so wie über ihr Verhalten gegen nascirenden Wasserstoff, die Haloïde u. a. m. werde ich in der späteren Abhandlung ausführlich berichten.

Indem ich von den Ergebnissen meiner bisherigen Versuche über das Isatin diese vorläufige Mittheilung mache, gebe ich mich der Hoffnung hin, dass, nachdem Baeyer mehr als zehn Jahre hindurch seine Versuche über Isatin und Indigo ohne das Dazwischentreten Anderer hat ausführen dürfen, man ähnliche Rücksicht auch mir zu Theil lassen werde. Ich bitte, mir nur den fünften Theil jener Zeit zur ungestörten Verfolgung meines Zieles zu gewähren.

Leipzig, im Juli 1884.

\section{Ueber die Zersetzung des Benzonitrils mittelst rauchender Schwefelsäure;}

von

\section{Fr. Gumpert.}

Um nach der Angabe von Pinner und Klein ${ }^{1}$ ) Kya-. phenin darzustellen, brachte ich je $10 \mathrm{Grm}$. Benzonitril in Kölbchen, welche durch Eis gekühlt wurden, und liess tropfenweise je $7 \mathrm{Grm}$. stark rauchender Schwefelsäure hinzutreten. So lange das Produkt gekühlt wurde, blieb es flüssig, wurde jedoch bei gewöhnlicher Temperatur fest, wobei sich geringe Wärmeentwickelung bemerklich machte. Nach 24 Stunden wurde die harzige Masse mit $W$ asser geschïttelt, der reichlich abgeschiedene Niederschlag aus Toluol und Benzol umkrystallisirt und dann der Analyse unterworfen. Der Schmelzpunkt

1) Ber. Berl. chem. Ges. 11, 764. 